\title{
La política como física del poder en Spinoza
}

\author{
Politics like a Physics of Power in Spinoza
}

\author{
Luciano EsPINOSA RUBIO \\ Universidad de Salamanca \\ espinosa@usal.es
}

Recibido: 05/04/2013

Aceptado: 20/02/2014

\section{Resumen}

La política consiste en la organización física y el desarrollo inmanente de la potencia natural de los individuos. Eso significa que los órganos constitucionales del poder soberano - cuyo sujeto es la multitud - son las partes de un todo concebido como un ecosistema abierto -que funciona como un individuo compuesto- y basado en ciertas características: las proporciones de sus elementos, un modelo de contrapesos descentralizado y la permanente regeneración de las estructuras. Esta complejidad sistémica hace mejor a la democracia porque permite mayor compatibilidad para que todos se expresen en libertad.

Palabras clave: política, poder, individuo, potencia, ecosistema, democracia.

\begin{abstract}
Politics consists in the physical organization and immanent development of the natural potency of individuals. That means that the constitutional organs of the sovereign power -whose subject is the multitude- are the parts of a whole conceived like an open ecosystem -it works like a composed individual- and based on some characteristics: the proportions of his elements, a decentralized and counterbalanced model and the permanent regeneration of its structures. This systemic complexity makes democracy better because lets more compatibility for everybody expression in liberty.
\end{abstract}

Keywords: politics, power, individual, potency, ecosystem, democracy. 


\section{Puntos de partida}

La hipótesis de trabajo es que la política está concebida, en primer lugar, como una fisica del poder en tanto que fijación de sus relaciones (casi cuantitativas), sus canales y equilibrios; y que la democracia, en segundo, es su mejor forma de organización por razones de complejidad sistémica. Por otro lado, se trata de un mismo modelo transversal que parte de la ontología de los modos (infinitos y finitos) y va desde la física hasta la epistemología, la ética y la política; y esta matriz común puede denominarse ecosistémica con fundamento, como habrá ocasión de ver. Además, lo físico debe entenderse de forma amplia, pues incluye las leyes de todo lo extenso y su correlato inteligible (entes naturales, organismos, impulsos psicofísicos primordiales... y sus ideas correspondientes), siempre en oposición frontal a cualquier clase de "cualidades ocultas" y entes extracorpóreos.

En un sentido más concreto, conviene recordar que la potencia (o essentia actuo$s a$ ) es el núcleo intensional de la realidad, su nervio constitutivo, lo que define a los modos finitos en términos eficientes (E1P36) ${ }^{1}$ y comporta de entrada un claro sesgo material en los seres vivos (E2P13: del cuerpo se accede al alma, que es su idea; E3P2E: autonomía de lo fisiológico). El resultado preliminar es una noción del poder humano investida de un carácter tangible y dinámico, acorde con la nueva ciencia de la época volcada en la explicación de las fuerzas. Semejante postura remarca el vínculo de ida y vuelta entre ser y operar, de modo que tal poder se efectúa en el ejercicio de las interacciones (de choque y composición con sus afectos correspondientes) que constituyen al individuo, lo que le va modelando a lo largo de su biografía. Y esto, a su vez, dentro del consabido marco general todo/partes (sustancia-atributosmodos infinitos y finitos), por lo que podría entenderse también como una teoría de campo, donde hay una estricta reciprocidad ecológica entre el adentro y el afuera que da lugar a la retroalimentación ${ }^{2}$ del sujeto. De ahí nace justamente la conciencia humana, que consiste en percibir los contactos ad intra y ad extra del cuerpo y procesarlos de manera autoconsciente (E2P23). En definitiva, aunque no podemos detenernos en ello y solo se desarrollará lo que atañe a la política, cabe hablar de una físicidad de carácter relacional, más rica - por abajo- que el simple mecanicismo de lo inerte, y ajena - por arriba- a cualquier forma de trascendencia.

\footnotetext{
${ }^{1}$ Utilizo las convenciones internacionales de citación según Studia Spinozana: E = Ética, $\mathrm{n}^{\mathrm{o}}$ de parte, Proposición, en su caso Escolio, Corolario, etc; TTP = Tratado teológico-político, capítulo y página de la edición de Gebhardt (1972); TP = Tratado político, capítulo y parágrafo; Ep = Epístola numerada. Sigo habitualmente las traducciones de Atilano Domínguez: E (2000), TTP (2003), TP (2004).

${ }^{2}$ Hago un uso libre -no técnico- pero cauto de categorías sistémicas o cibernéticas actuales, en la medida en que hay algunos elementos del armazón político - que es lo único que nos ocupa-susceptibles de ser interpretados y clarificados así.
} 
Importa subrayar esto en todas las instancias: en clave metafísica, Dios no es diferente - por tratarse de términos unívocos e inmanentes- de la Naturaleza; en clave hermenéutica, la Escritura no tiene un sentido misterioso que rebase al texto literal elaborado con el cuerpo de la lengua; en clave jurídica, la ley no basta sin el poder que la respalda, que es fuerza y capacidad efectiva de coacción; en clave psicológica, entendimiento y voluntad se identifican y no son nada aparte de las ideas que los expresan en cada momento; en clave ética, la virtud se encarna en los afectos mismos que implican aumento de potencia, no es un resultado posterior... ${ }^{3}$. Esto quiere decir que la afirmación del ser, en sus diferentes registros, no admite equivocidad o analogía, ni suplementos de valor y sentido venidos de fuera, ni consideraciones sobre lo que puede llegar a ser después: cada ente es lo que es en cada caso y momento, sin teleología ni trasfondo moralizante añadidos, sin virtualidad diferida...

Bajo este punto de vista, la física significa pura facticidad ontológica, cuerposideas-afectos correlativos aquí y ahora, explicitud de la potencia siempre en acto, realización ejecutiva. Algo que no debería confundirse con un mero positivismo o materialismo reduccionista, sino entenderlo más bien como el empeño de no escamotear lo que las cosas son efectivamente, de no caer -visto desde otros ángulos- en hipóstasis o trascendentales, en vaguedades sobrevenidas o legitimaciones externas... ${ }^{4}$ Pues bien, la política también responde a estas notas generales, donde lo crucial es que el campo enorme de lo simbólico nace de la inmanencia física, y no al revés, aunque luego formen un círculo virtuoso. Por lo mismo, la libertad no es una cualidad espiritual dada de antemano, sino que debe alcanzarse mediante la expresión de la propia potencia o naturaleza (formas estables de necesidad ${ }^{5}$ emancipadora) que permitan una acción verdaderamente humana frente a la fatalidad de los contextos naturales o las imposiciones de los tiranos.

En otro orden de cosas, es ilustrativo observar los diferentes ámbitos de la vida tal como son condensados en E4P18E: los “dictámenes de la razón” establecen un nexo y una secuencia clara entre autoconservación del conato / virtud y felicidad / apertura e intercambio con el medio / composición y concordancia racionales entre los hombres / utilidad común lograda por la constitución de "un solo cuerpo y una sola alma" de carácter sociopolítico. La idea global es que la potencia (de ser y pensar) es versátil y está llamada a dar de sí todo eso en el plano de la acción humana que participa de la potencia divina (E4P4), lo que implica el establecimiento de diversas conexiones entre

\footnotetext{
${ }^{3}$ Puede ampliarse el tema y ver un compendio en torno a esta posición en Montag, W., Cuerpos, masas, poder, Madrid, Ed. Tierradenadie, 2005.

${ }^{4}$ Cf. en la misma línea general, García del Campo, J. P., "Multitud e individuo compuesto", en M. Galcerán y M. Espinoza (eds.), Spinoza contemporáneo, Madrid, Tierradenadie ediciones, 2009.

${ }^{5}$ Aquí, como en E1D7, la libre necesidad (interna) de la propia naturaleza es autonomía y afirmación de sí, opuesta a la coacción (externa) o heteronomía. De ahí, por ejemplo, que Spinoza sea contrario a la predestinación (TTP, prol.).
} 
lo ético y lo político, así como el engarce del poder personal y del colectivo, como se acaba de ver en esa secuencia. Cuanto quede fuera de esas coordenadas o niveles de experiencia es considerado una fantasmagoría idealista o una variante de la ignorancia. Por el contrario, la dinámica de los cuerpos (y por tanto de las ideas) se traduce en comunicación, afectos y fuerzas de diversa índole, lo que configura un tejido de relaciones favorables o no dentro del cual se desenvuelve la existencia. Y el caso es que todo ello acontece en un campo de juego neutro, es decir, amoral: en la naturaleza nada está prefijado, no hay valor dado de antemano, orden ni dirección de sentido, tan solo la implacable sucesión de los encuentros causales y el esfuerzo intersubjetivo por concertarlos un poco. La política, entonces, emerge como el proyecto de gobernar la física humana y sus muchas implicaciones institucionales (lingüísticas, organizativas, simbólicas, etc.), toda vez que -como subconjunto de lo real- esas fuerzas son la infraestructura de la sociedad y de la cultura, sometidas a unas pautas comunes de articulación.

\section{Algunos rasgos de la política}

En la delimitación que Spinoza hace del quehacer político para ver cuál es el propósito esencial y en qué forma encajan las piezas, parece fecundo pensar que su reconocido ideal republicano está mucho mejor servido precisamente por una lectura física de los agentes y las interacciones. Lo que además permite certificar que nos hallamos ante una empresa realista en los varios sentidos de la palabra, lúcida y viable, capaz de ligar las condiciones de hecho y las de derecho, esto es, las características naturales del mundo y el proyecto liberador de los hombres.

2.1. Así, cabe hablar de una posición de principio que sitúa bien el tema: es una política de la finitud que descarta todo lo que no quepa en el lenguaje inmanente del poder y que plantea la discusión en un territorio no sólo ajeno a cualquier iusnaturalismo o designio exterior, sino también al margen de la verdad o la bondad como fines. Y es que se pretende explicar un ajuste o engranaje de elementos (cuerpos, afectos, intereses, grupos, etc.) que funcione eficazmente con la menor violencia posible -el "rozamiento" del dispositivo- y satisfaga las demandas de utilidad para la mayoría. De lo que se trata es de buscar la cooperación entre individuos "singulares y finitos", susceptibles de concurrir a "una misma acción, de tal manera que todos a la vez sean causa de un solo efecto" (según enuncia la pauta física general de E2D7), y ello porque articulan sus respectivas potencias en una multitud (multitudo) que se convierte en la protagonista final de todo régimen ${ }^{6}$. Digamos que esta

\footnotetext{
${ }^{6}$ Incluso en la monarquía, la multitud es la última referencia pues en ella reside el derecho civil o poder de la sociedad, que luego se traspasa al rey, pero nunca de manera absoluta e irreversible (TP 7/25).
} 
suerte de laicismo discursivo (no estamos ante una política edificante) tiene algo de ingeniería de lo finito en la medida en que supone el paso desde la "ley suprema de la naturaleza" que afirma la universal tendencia a la autoconservación (TTP 16:189) hacia la más concreta "ley universal de la naturaleza humana" que funda la posibilidad de todo pacto (TTP 16: 191): los hombres y las mujeres actúan regidos por la "verdad eterna" de su naturaleza que los hace sentir miedo ante lo que consideran un mal mayor y esperanza ante un bien mayor, aparte de que en todo caso eligen siempre lo que suponen el mal menor, de ahí que cualquier pacto tiene su razón de ser en la sola utilidad evaluada según estas premisas pasionales (TTP 16: 192). Entender así el principio que gobierna las conductas -lo que ya presupone que el deseo individual requiere de otras potencias para desplegarse y afrontar el entorno- permite fundar una política cifrada en el mínimo común denominador de vivir "con seguridad y sin miedo" (TTP 16: 191), que es la puerta de la libertad. La política canaliza y usa adecuadamente la esperanza y el miedo, rebasando las meras pasiones subjetivas hacia una administración colectiva de las mismas, para generar tantos beneficios como sea posible. Luego hay primero una mirada de entomólogo, afincada en la comprensión sin prejuicios de la naturaleza humana, y después pragmática en el manejo de sus resortes primordiales.

2.2. Por otro lado, hallamos una concepción general de la política que bien puede denominarse artificialista: es sabido que en este enfoque prima el posibilismo, no la utopía, alimentado con la experiencia y la enseñanza histórica de quienes han gestionado la cosa pública desde dentro (TP $1 / 2$ y 1/3). No hay recetas ni seguridades, sino un arduo aprendizaje basado en conjuntar la razón y el continuo ensayo y error. Para desbrozar el terreno, Spinoza advierte que el derecho natural no es otra cosa que potencia en estado bruto ("jus sive potentia", TTP 16: 189 s.; TP 2/8), lo que supone el imperio del deseo arbitrario de cada uno hasta donde llegue su fuerza, a no ser que se instaure un ámbito de derecho civil en el que se fomente la libertad compartida como nuevo ingrediente de lo anterior ("sive libertas"). Pero también ahí se impone una visión física del poder legal: sólo se tiene el "derecho de mandar" cuando se conserva en activo "la potestad suprema" que resulta de la transferencia de poder de los sujetos (TTP 16: 194), es decir, un monopolio de la fuerza que se aplica efectivamente en la praxis. Luego nos encontramos ante la difícil construcción institucional del poder civilizado, que es algo siempre vivo y capaz de cambiar, reconfigurarse o fracasar.

Debe añadirse que esta perspectiva que aúna naturalismo y constructivismo encaja muy bien con la llamada a la transacción negociada, por medio del debate, de la consulta y del ensayo de diferentes medios (TP 9/14); esto es, el ejercicio inequívoco del poder es compatible con la flexibilidad ante las muchas dificultades y ava- 
tares de la política. Ductilidad que guarda relación también con aquellos lugares en que el autor se refiere a la vida cotidiana y sus circunstancias irreductibles a normas abstractas o leyes generales, por lo que no queda otro remedio que recurrir a lo "verosímil" (Ep. 56: 260), a la "certeza moral" o a una verdad provisional cuando no haya otra (TTP 15: 185 y 187). La dureza de la existencia obliga a sumar fuerzas y aprovechar los indicios o las mejores conjeturas, amén de los consensos básicos de una cultura, sean o no racionales del todo: con frecuencia hay que vivir como si las cosas fuesen lo que parecen y se pudieran manejar. Todo lo cual nos sitúa definitivamente en el ámbito del falibilismo más consciente, con sus dosis aceptadas de buena voluntad, incertidumbre y gradualismo en la praxis, algo que matiza y completa lo dicho más arriba sobre la política como ingeniería. La razón propone y las circunstancias más los afectos, al menos en parte, disponen.

2.3. Por último, es adecuado referirse a la intención subyacente que dirige a largo plazo esta clase de actividad, una vez satisfechas las necesidades urgentes de la convivencia, y que no es otra que la educación y terapia de los afectos: al afirmarse que hay una propensión "innata" a la vida social (TP 6/1) y que el hombre no nace civilizado, sino que se hace en todos los aspectos relevantes (TP 5/ 2, 3 y 15), es fácil concluir la importancia de encauzar su espontaneidad para evitar el sufrimiento y promover la dicha. Spinoza no escatima comentarios descarnados sobre las pasiones más habituales (el egoísmo, la envidia, la soberbia, la mendacidad, la pereza, la avaricia, etc.) y sus consecuencias, lo que indica una proclividad a todo cuanto enfrenta y divide (véanse los elocuentes ejemplos de E3P55E1; TP 1/5, 7/4). Y esas tendencias son las que hay que abordar prioritariamente en términos políticos: dado que la sola razón ofrece un camino privado "extremadamente difícil" para someter y moderar las pasiones, el pensador holandés atribuye una responsabilidad directa al Estado respecto a las virtudes y los vicios de los individuos que lo habitan (TP 5/3), pues mucho hay de cura y pedagogía en su función según como esté organizado. Es imprescindible una suerte de maquinaria institucional que asegure la fluidez y la descompresión de los conatos, esto es, que alivie los conflictos, aproveche las energías y dé solución a las exigencias básicas, lo que redunda en bienestar general. La política -en este sentido casi mecánico- sirve para garantizar la circulación de los deseos y la evacuación de las tensiones, sin olvidar cierto grado de debate, pero además es capaz de transformar ese potencial afectivo en la consecución de concordia y de productividad.

A nadie se le oculta el carácter antinómico de algunos aspectos en tan difícil empeño (libertad-igualdad, autonomía-obediencia, etc.) y la perenne tragedia del quehacer humano, a menudo frágil e incapaz de conciliarlo todo. Por eso hay que evitar tanto la "solución impecable" (coincidencia perfecta de ética y política, justicia y libertad, armonía...) como la "solución implacable" (primado de la cohesión y del bien 
común, autoridad fuerte, control social, seguridad... $)^{7}$. Spinoza intenta una vía alternativa que coordine en alguna medida ambas opciones, desde la constatación de que no pueden coincidir por completo, como tampoco encajan siempre razón legal y razón de estado, de ahí quizá las fluctuaciones que algunos han señalado en sus textos. Sin embargo, hay que ver esta ambivalencia como un signo de madurez y de complejidad frente a la simplificación dogmática y supuestamente clarificadora. Lejos del pesimismo y del optimismo, de las soluciones retóricas, de la renuncia o del consuelo vacuo ante lo ineluctable, se trata de hacer propuestas útiles con exigente afán reformista, desde un posibilismo que no claudica. La autodeterminación de los Estados y de las personas es siempre limitada e insatisfactoria, pero la buena arquitectura de las instituciones, la prudencia en la gestión y los ideales republicanos de participación ciudadana resultan buenas herramientas.

El asunto gira entonces en torno a una buena organización del poder (cifrada en la composición del todo y de las partes, como en el resto de su pensamiento), de manera que la discusión no es moral, ideológica o económica, en sentido convencional, sino de otra índole: cómo generar una construcción solvente donde las fuerzas y los equilibrios se decanten casi por sí mismos ${ }^{8}$. Así, las estructuras y contrapesos tienen el protagonismo frente a las decisiones personalistas y al voluntarismo (sea o no heroico), algo que le distancia en este punto del genial príncipe maquiaveliano no menos que del macizo y monolítico leviatán hobbesiano. En resumen, una buena física del poder entendida como la mejor defensa contra la arbitrariedad, la opresión y el devenir siempre inestable de los asuntos humanos, es decir, como una malla protectora que aglutina y deja margen a la vez.

\section{Modelos ecosistémicos de organización}

La política no refunda la metafísica, sino que la prolonga en tanto que expresa su trasfondo físico hasta convertirlo en una especie de plantilla de cohesión formal y material entre individuos. Se tiene que establecer un derecho común que proporcione claras ventajas a sus partícipes (TP 2/13; E4P35E), o, dicho de otro modo, articular las potencias en términos recíprocos y voluntariamente auto-hetero-regulados. Lo in-

\footnotetext{
${ }^{7}$ Cf. Del Águila, R., La senda del mal, Madrid, Taurus, 2000; en especial el cap. III: "Pesadillas modernas", pp. 165-208. Las pasiones, los principios racionales y la fortuna son los tres ingredientes principales de la empresa política, según los grandes tratadistas, y es necesario asumir su imposible conciliación definitiva, cf. p. 82.

${ }^{8}$ En este punto hay un interesante paralelismo con el pensamiento político chino, a propósito de captar y conducir las propensiones naturales de las cosas: sea con lo que representa el legismo, como en Han Fei, según el cual la ley opera por sí misma casi sin intervenciones de los sujetos; o mejor en términos más flexibles y no autoritarios (búsqueda de equilibrios, de bienestar material por medio de la razón...) con el confuciano Xun zi. Pero ése es otro tema.
} 
teresante del caso es que hay complementariedad, antagonismo o mera concurrencia entre los ciudadanos, en distintos planos, algo que permite concebir el Estado como un ser animado, susceptible de reorientarse gracias a sus diferentes circuitos de interacción corpórea, anímica, simbólica, etc. La tarea básica es gestionar racionalmente la cantidad de sujetos (de entrada los muchos cuerpos), lo que supone crear vínculos en el seno de la multitud a su vez sostenidos por la "unión de las mentes" (TP 3/2,7; mentes que son -no se olvide- las ideas de los cuerpos, según E2P13), para que eso se traduzca luego en calidad de vida con sus diversos registros.

3.1. Y para lograrlo es necesaria una estructura físico-social aglutinante, sobre la cual descansen y sean posibles dos claves decisivas que consisten en establecer un círculo virtuoso entre razón y civitas (TP $2 / 21)^{9}$, por un lado, y entre seguridad y liber$\operatorname{tad}$ (TTP 20: 240s.) ${ }^{10}$, por otro. Es cierto que a menudo chocan, pero cada uno de los miembros de un par no puede cualificarse sin el otro, por lo mismo que ambas parejas se necesitan y fortalecen entre sí, a partir de aquella organización de base. Spinoza no renuncia a esa conjunción, más dialógica que dialéctica: se constituyen mutuamente y la oposición queda subordinada a su carácter correlativo, sin que eso suponga el desarrollo de un proceso inexorable ni sean reducibles a un fondo de identidad. Dadas unas condiciones mínimas en esta línea, las personas pueden expresar sus capacidades bajo un doble signo que incluye tanto constricciones que aseguran la paz como facilidades sociales y de comunicación en forma de deberes y derechos, sin olvidar la ayuda mutua y los aprendizajes culturales o la racionalidad y los afectos compartidos; en resumen, la confianza en lo público sin perder la iniciativa particular.

El proceso político es causa y efecto de todo ello en un sentido global, pero también recursivo, pues ordena y moviliza esas instancias en un primer momento a la par que recibe e integra los frutos después, en ciclo abierto y sin fin. El poder es más emancipador si resulta autoconsistente, por eso recalca el autor que, con independencia de la actitud y motivos de los dirigentes, para que el Estado "pueda mantenerse, sus asuntos públicos deben estar organizados de tal modo que quienes los

\footnotetext{
9 "Sin embargo, como la razón enseña a practicar la piedad y a mantener el ánimo sereno y benevolente, lo cual no puede suceder más que en el Estado; como, además, no se puede conseguir que la multitud se rija como por una sola mente, cual debe suceder en el Estado, a menos que goce de derechos establecidos por el dictamen de la razón...".

10 "De los fundamentos del Estado... se sigue, con toda evidencia, que su fin último no es dominar a los hombres... sino, por el contrario, librarlos a todos del miedo para que vivan, en cuanto sea posible, con seguridad (...) El fin del Estado repito, no es convertir a los hombres de seres racionales en bestias o autómatas, sino lograr más bien que su alma y su cuerpo desempeñen sus funciones con seguridad, y que ellos se sirvan de su razón libre y que no se combatan con odio... El verdadero fin del Estado es, pues, la libertad". El desarrollo de la razón depende ya de ese mismo proceso político que aparta obstáculos y facilita las cosas en todos los órdenes.
} 
administran, tanto si se guían por la razón como por la pasión, no puedan sentirse inducidos a ser desleales o a actuar de mala fe (...). La libertad de espíritu o fortaleza es una virtud privada, mientras que la virtud del Estado es la seguridad" (TP 1/6). Todo depende, pues, de la estructura política y sus mecanismos de previsión (entre los que destacarán -como veremos- los de tipo procedimental y de fiscalización de los actos, así como los contrapesos institucionales), con el propósito de que estas condiciones objetivas aseguren la estabilidad, disuadan de las malas prácticas y garanticen el respeto al orden legal. La seguridad es la virtud del todo que nace del buen funcionamiento de las partes y garantiza su equilibrio, lo que a su vez permite promover la libertad (según el círculo citado más arriba), ya que son anverso y reverso de lo mismo: la primera crea las condiciones de la segunda (paz, leyes, puesta a punto de recursos y servicios públicos...) y ésta fortalece a aquélla por el consenso de quienes apoyan al sistema que los hace libres.

3.2. Por otro lado, es obvio que ese modelo de organización guarda semejanza (aun con las variantes propias de cada régimen) con la organización física de los llamados individuos compuestos, en particular con los humanos y sus peculiaridades psicofísicas. No en vano añade Spinoza que "los fundamentos naturales del Estado no habrá que extraerlos de las enseñanzas de la razón, sino que deben ser deducidos de la naturaleza o condición común de los hombres" (TP 1/7), y nada mejor que empezar por su constitución orgánica. Es indicativo que subordine la vía de la razón, acaso más abstracta e ideal, a esta otra más naturalista que incluye los aspectos fisiológicos y después las pasiones, habilidades, necesidades y propensiones que determinan la vida social. Puede decirse que la política, en cierto modo, imita y recrea -no sólo utiliza- la psicofisiología de los individuos, enriqueciéndola con nuevos ingredientes, para construir con tal apoyo en la realidad humana ese artefacto terapéutico que gestiona la finitud, es decir, el Estado que a la postre todo lo religa.

De forma muy resumida ${ }^{11}$, el término ecosistema significa aquí un conjunto articulado de partes en interacción regido por constancias internas y por un intercambio esencial con el medio, de manera que se trata de un sistema abierto en el cual el adentro y el afuera son rigurosamente recíprocos. Como es sabido, para Spinoza la constitución ad intra de un sujeto físico $(\mathrm{X})$ se funda en una proporción de movimiento y reposo (en adelante $\mathrm{M} / \mathrm{R}$ ) que une otras partes corpóreas: es una suerte de información de primer orden (en cuanto que da forma y organiza) flexible, dado que no hay una cantidad absoluta sino relativa (una ratio justamente llamada proporcional); lo

\footnotetext{
${ }^{11}$ He tratado por extenso el tema en mi libro Spinoza: naturaleza y ecosistema, Salamanca, UPSA, 1995. Ahí se recogen las aportaciones de obras precursoras como la de Peña, V., El materialismo de Spinoza, Madrid, Revista de Occidente, 1974; pero se intenta aportar nuevos elementos hermenéuticos.
} 
que a su vez expresa una cantidad de potencia individual. Y estas cantidades correlacionadas de materia y de potencia varían -dentro de unos márgenes- en función del comercio con el entorno que las alimenta y activa, por así decir, dado que ad extra los individuos son parte de un conjunto. La formación de los individuos, según E2P13, obedece al movimiento, dirección, velocidad, superficie, tamaño, etc., de los cuerpos simples (x) que conforman sujetos mayores de diferente grado de composición $(2 \mathrm{X}, 3 \mathrm{X}$, etc.), hasta desembocar en el escolio del Lema 7 que sintetiza la teoría general: hay una articulación de individuos en escala creciente (se componen entre sí por niveles hasta constituir el todo, cuya proporción $\mathrm{M} / \mathrm{R}$ resulta de coordinar las otras proporciones por niveles, inclusivas entre sí), lo que supone cambios y modos variables de afectar y ser afectados en cada nivel, pero sin alterar la naturaleza del conjunto. El resultado es una concepción de la naturaleza entera como "un individuo, cuyas partes, esto es, todos los cuerpos, varían de infinitos modos, sin cambio alguno del individuo total". El lenguaje físico es muy fructífero para describir lo que en última instancia es un modelo de integración, comunicación y cooperación/lucha de individuos compuestos en un marco de articulaciones ilimitadas.

Todo individuo presenta, pues, varias dimensiones (material, informacional, de potencia) y tiene una doble identidad, interna y externa, por lo que su ser consiste en una especie de intersección sustantiva de todo ello. Sin olvidar que lo afirmado del cuerpo tiene su correlato en la mente a todos los efectos, en virtud del famoso paralelismo (E2P7) que los entiende como dos expresiones de la misma realidad. Se trata, dicho de otra manera, de un proceso de auto-eco-constitución cifrado en el devenir de una forma de organización singular estable (M/R-esencia-potencia), atravesada por la circulación de materia, energía e información (también de segundo grado: ideas en la conciencia), que da lugar a diferentes capacidades de ser y pensar, con el consiguiente empeño en autorregularse para mantener una homeostasis adaptativa y crecer en fuerza. Los intercambios con el medio producen retroacciones constantes (reajustes mediante computación de datos y asimilación de elementos), sin rebasar o romper la elasticidad característica de la propia identidad, pues supondría la muerte, y si es posible haciéndola más inteligente. Es lo que el autor judío define como la dinámica de las afecciones o contactos entre cuerpos (y sus ideas correlativas, los afectos), que hacen aumentar o disminuir la potencia (E3 Def. y postul., Aff. Def.) ${ }^{12}$; algo que en el caso humano se hace mucho más denso, pues hay idea de la idea o autoconciencia precisamente surgida de ese trato con el mundo: "El alma no se conoce a sí misma sino en cuanto que percibe las ideas de las afecciones del cuerpo" (E3P23). Y ahí nace la posibilidad de

\footnotetext{
12 "Por afecto entiendo las afecciones del cuerpo, con las que se aumenta o disminuye, ayuda o estorba la potencia de actuar del mismo cuerpo, y al mismo tiempo las ideas de estas afecciones" (E3 Def.3). Por su parte, el Postulado 1, referido a la capacidad de ser afectado del cuerpo humano y su correspondiente cambio de potencia, remite directamente a la física que nos ocupa (E2P13).
} 
gobernar esos avatares físicos y afectivos en la medida en que los comprenda y produzca otros afectos (que son fuerzas) como su causa adecuada, dando lugar a una acción alegre, en vez de una pasión triste. Es un proceso siempre abierto de retroalimentación que genera nuevas actualizaciones del ser y se despliega de maneras diversas (orgánicas, cognitivas, emocionales), pero aquí basta con dejar constancia de las raíces físicas de la epistemología y de la ética, a través de una lectura de sus fuerzas activas o pasivas, asentadas en un entramado ecosistémico (interno y externo).

Debe repararse con sumo cuidado en la mirada relacional del discurso, al menos en tres niveles: a) se rechaza por igual el holismo y el atomismo, en términos metodológicos generales; b) se proponen vías de composición de la pluralidad, sea para conjuntar lo diferente o para articular sujeto y mundo, autoconciencia y realidad; c) se evita por igual el mecanicismo cartesiano y el animismo leibniziano para situarse en una posición intermedia (que ahora no cabe desarrollar). Hay una cierta complejidad (la información que nos vertebra, que hoy llamaríamos biológica) es soporte o plataforma del resto de dimensiones (informaciones mentales de otros grados), lo que establece un tejido conectivo entre esos niveles y desemboca en el antidualismo que elimina otras instancias (alma trascendente, dotación innata, voluntad ilimitada...). La dimensión ecológica así entendida se aprecia en las relaciones internas entre partes distintas del cuerpo, en los vínculos capitales de éste con el exterior y en el surgimiento de la consciencia humana, así como en la orientación genérica de su praxis (comprender y transformar). El esquema es relativamente sencillo, acorde con su tiempo, pero polivalente a la hora de aplicarse a la epistemología (las llamadas nociones comunes son sistemas cognitivos o federaciones de ideas/objetos basadas en lo común), a la ética (como estilo de vida es resultado de la proporción de ideas adecuadas e inadecuadas) y a la política (basada en otras proporciones y federaciones que pronto serán examinadas). Pero véanse en acción a través de la especificidad del cuerpo humano y de las posibilidades correlativas de la mente (o idea de ideas).

La capacidad del alma humana se funda en las cualidades del cuerpo y en cierto modo le convierten en modelo de referencia como individuo complejo: está muy compuesto de otros cuerpos menores de diversas naturalezas y constituciones materiales, lo que incrementa en extremo su caudal de afecciones por parte de cuerpos ajenos; requiere de "muchísimos" de éstos para ser "continuamente regenerado", además de guardar los vestigios de los contactos y tener la facultad física de "mover y disponer de muchísimos modos los cuerpos exteriores" (E2P13Postul). Lo primero a destacar es el uso continuo de superlativos, ya que Spinoza subraya que el cuerpo humano es muy complejo y colma las aptitudes antes enunciadas: riqueza interna de composición y versatilidad consecuente, plena apertura al entorno para recibir energía y afecciones -de las que queda registro-, y capacidad para actuar con eficacia. Lo cual le permite regenerarse y combatir la entropía, amén de facilitar fisiológicamente lo que será la creación intelectual, técnica y social, pues una vez más estos planos se com- 
plementan y refuerzan. A la información que nos constituye (ratio de M/R como organización de partes en un todo) se suma la información que proviene del exterior y la que es acuñada culturalmente, de manera que -ya más ricas de lo habitual en otros cuerpos- se entrelazan y fundan la conciencia subjetiva. Queda inaugurado el vasto campo de "la experiencia y del conocimiento", recíproco de la observación y la transformación de las cosas, lo que reporta múltiples utilidades que empiezan por conservar el cuerpo (alimento, ejercicio, placeres) y la consiguiente potenciación del alma (E4Ap27), de manera que este segundo aspecto de la praxis humana revitaliza aún más aquel organismo. Importa insistir en la plasticidad (dentro de ciertos límites) que será moldeada por los afectos ("la constitución del cuerpo o el afecto es lo mismo", según E3P18), con la correspondiente repercusión sobre la potencia de ser y pensar, que a su vez da lugar a los grandes tipos o estilos de vida adoptados. La intención de fondo es que, tal como se avanzó, el sujeto llegue a dirigir su existencia mediante una buena proporción de ideas adecuadas respecto a las inadecuadas y que sea activo en vez de impotente (E5P20E). Y la hipótesis reiterada es que este esquema puede aplicarse también al gobierno del Estado (sacando todas las consecuencias sobre el individuo compuesto que es), con las transposiciones oportunas.

3.3. La meta es regular los contactos físicos y simbólicos, es decir, permitir un juego de órdenes y desórdenes limitados, intercambios y acuerdos, que a la postre encajen sin colapsar el sistema. La física del contacto implícita (opuesta a la acción a distancia de los newtonianos) supone en este ámbito la plena inmanencia del poder, que radica en los individuos y actúa por continuidad. Hay que establecer -como en los cuerpos- una relación de relaciones, una articulación de individuos que se componen en sociedades sin perder la fecunda tensión de la unidad y la diferencia. Semejante concordia discordante se teje hasta constituir redes, que son las instituciones y las leyes que las hilvanan (las "nociones comunes" de la política), bajo diversas configuraciones y regímenes, tal como hay distintas mentes/cuerpos personales según sus constituciones orgánicas y aprendizajes respectivos. El poder es al cabo la proporción establecida entre las potencias particulares, es decir, la coordinación de fuerzas entre sujetos y, de modo indirecto, entre grupos, intereses, normas, afectos, idiosincrasias, etc., donde lo prioritario es que haya una co-acción compartida opuesta a la habitual coacción represora. Además, este trasfondo físico más que simbólico ${ }^{13}$

\footnotetext{
${ }^{13}$ Podría incluso decirse que Spinoza no atiende lo suficiente a la dimensión imaginaria del poder, es decir, que no valora lo bastante la puesta en escena, la iconografía y la prosopopeya convencionales, el boato y el protocolo, etc. (cf. Balandier, G., El poder en escenas. De la representación del poder al poder como representación, Barcelona, Paidós, 1994). Es coherente con su rechazo de todo signo como forma de trascendencia, pero minusvalora su importancia efectiva, es decir, eficiente. Además, está lejos de lo que C. Castoriadis ha llamado la institución imaginaria de la sociedad, esto es, la creación histórico-social de sentido y significado, la matriz radical de inter-
} 
supone la identificación rigurosa entre forma y proceso: la estructura ya es algo dinámico que está en marcha, pues el Estado es una organización siempre operativa, al igual que los cuerpos y su capacidad de afectar y ser afectados.

Por otro lado, el sentido horizontal es claro, lejos de las metáforas verticales del barroco (cono, pirámide...) tan habituales en Leibniz, por no hablar de la "armonía preestablecida" de mónadas aisladas (que sin embargo ofrecen una perspectiva del universo), algo ajeno por completo a esta ardua composición de individuos mediante el contacto, donde no hay garantías de acuerdo armónico ni luces cenitales que iluminen el escenario. Lo que sí cabe es considerar a cada sujeto como una especie de holograma -no perspectivista- del universo y de la sociedad, en tanto que es una parte en la que está presente a escala el todo: participación de lo extenso y lo pensante, proporción de $\mathrm{M} / \mathrm{R}$, potencia..., más el aprendizaje de los códigos culturales en el caso humano. Y a la vez el Estado se rige por la lógica de los cuerpos individuales, de modo que las partes juntas conforman un todo único, mejor o peor ajustado en cada país y régimen. Impera, no obstante, una visión ligada a la naturaleza (sincronía) antes que al curso lineal y acumulativo de la historia (diacronía), con las luces y sombras que ello supone: Spinoza no concede importancia sustantiva al tiempo -aunque tampoco lo olvide y abunden las referencias históricas y otras experiencias para completar el dictamen racional ${ }^{14}$-, algo que le libra de la servidumbre teleológica del historicismo pero también dificulta mucho la comprensión de los procesos de larga duración y de cambio cualitativo. Diríase que pretende poner la organización política a salvo de los sobresaltos del devenir buscando un denominador común atemporal, tal como hacen las leyes físicas.

\section{Los registros y engranajes del poder ${ }^{15}$}

De entrada, hay que referirse a ciertas proposiciones-puente (situadas juntas, por cierto, lo que habla de una intención expresa) que el autor tiende desde la infraes-

\footnotetext{
pretación que genera un mundo (no reducible a ninguna infraestructura), y en cuyo seno emergen las formas de poder. Pero ése es también otro tema.

${ }^{14}$ Esto a veces supone abrir las costuras del sistema y enriquecerlo empíricamente, como he tratado de mostrar en "Historia, naturaleza humana y experiencia como nociones transitivas en Spinoza”, en Carvajal, J. y De la Cámara, M. L. (eds.), Spinoza, de la física a la historia, Ciudad Real, Universidad de Castilla-La Mancha, 2007, pp. 353-369.

${ }^{15}$ Este apartado se basa en mi artículo "Spinoza: la naturaleza ecosistémica de la política", Papeles de la FIM, $\mathrm{n}^{\circ} 4,2^{\circ}$ semestre 1995, pp. 81-92. Compruebo que los aspectos cuantitativos y "externos" (aquí decimos físicos) de la política también son considerados prioritarios en la introducción de Ch. Ramond a su edición de Spinoza: Oeuvres V. Traité Politique, Paris, PUF, 2005 (según la reseña de $\mathrm{M}^{\mathrm{a}}$ Luisa de la Cámara, Boletín de bibliografía spinozista, $\mathrm{n}^{\circ}$ 8, p. 385, en Anales del Seminario de Historia de la Filosofía, vol. 23, 2006).
} 
tructura corpórea hacia el terreno ético y político. Así, se considera útil cuanto favorece la aptitud del cuerpo para el intercambio con el exterior (afectar y ser afectado) y nocivo a su contrario (E4P38); de igual forma que es bueno en sentido básico todo aquello que favorece la proporción de M/R y malo cuanto la perjudica (E4P39); para concluir diciendo que es útil aquello que promueve la concordia en la sociedad y malo lo contrario, dado que esa paz y ajustamiento ayudan a que el hombre viva bajo la guía de la razón, lo que a su vez permite expresar la naturaleza de cada uno, así como apreciar a los demás en tanto se coincide racionalmente con ellos (E4P40, que remite a E4P35). De la física se pasa a los otros dos ámbitos por un mismo hilo conductor: es beneficioso cuanto favorece la apertura y la coordinación, de manera que la capacidad de percibir e interactuar es la mejor aliada para la estabilidad del individuo y esos rasgos son fuente de regeneración permanente, de cooperación y a la postre preparan la racionalidad. Podría hablarse incluso de un boceto transversal de antropología, fundado en lo que es propio de los cuerpos humanos y sus proyecciones prácticas (sin romper la homogeneidad natural básica de todos los seres, cf. E3Prol.), donde las valoraciones (útil/nocivo, bueno/malo) están ligadas en su raíz al modelo físico de concordancia y composición.

Afirma Spinoza que debe pasarse de la "persona natural" a la "persona social" en sentido político (a propósito del hecho de detentar y repartir el poder, TP10/2), y al amparo de este concepto es viable decir que el Estado (imperium) se conforma bajo tres aspectos: a) un cuerpo (según expresión literal del autor) constituido por los ciudadanos o individuos asociados (cives, civitas), que tendría un carácter funcional y es depositario del poder en todos los sentidos; b) una mente (según mi hipótesis) que se refiere a la constitución o estructura que los articula institucional y legalmente (status civilis); y c) la dinámica análoga a los afectos activos y pasivos (según mi lectura) que viene dada por la administración y gestión de los asuntos públicos (respublica) por parte de la autoridad (todo en TP $3 / 1^{16}$ ). Spinoza llama expresamente mens del Estado al "derecho de las supremas potestades" (TP 4/1), lo que encaja con el punto b) anterior, donde se codifica y legitima el poder decisorio de éstas, cedido por los ciudadanos; y después se refiere a las "funciones" y los "medios" que conciernen "a la totalidad del cuerpo del Estado" como los instrumentos propios de la "gestión" que lleva a cabo la suprema potestad (TP 4/2), lo que parece acorde con los puntos a) y c) mencionados: los ciudadanos ejecutan las actividades que les son propias, así como los cuerpos interactúan con el medio y son fuente de información-afectos para la mente.

Que el Estado es un individuo compuesto no ofrece lugar a dudas, pero añadir esta caracterización específica del individuo humano lo perfila más en sus aptitudes. Y el

\footnotetext{
${ }^{16}$ Atilano Domínguez se refiere en su edición del TP (Madrid, Alianza Editorial, n. 18, p. 82) a esa misma tripartición, si bien no entra en esta línea interpretativa y sus extrapolaciones.
} 
esquema es adaptado a cada uno de los regímenes políticos (monarquía, aristocracia y democracia), según sus elementos particulares: por ejemplo, el Rey es el "alma" de la sociedad y su Consejo Real "los sentidos externos del alma” y por extensión "el cuerpo de la sociedad" al que representan, los cuales perciben y actúan en nombre de aquél (TP 6/19). En cualquier caso, lo que importa es que haya identidad psicofísica y fluidez entre las partes, para que la conducta del Estado sea lo más eficaz posible mediante el ejercicio de las funciones, de modo que los diversos actores del poder cumplan bien su cometido en beneficio de la salud general. Y para lograrlo conviene atenerse a ciertas pautas de organización, cuyo desglose podría incluir cuatro aplicaciones del modelo ecosistémico, relativas a diferentes dimensiones del individuo político. He aquí un resumen (loc. cit. en nota 14, p. 87 ss.):

4.1. Por analogía con la proporción de $\mathrm{M} / \mathrm{R}$ que organiza a los cuerpos en clave de partes/todo, se impone la búsqueda de proporciones adecuadas entre el número de ciudadanos (y sus diferentes grupos) a representar, por un lado, y el número de puestos de gestión y/o representación en las instituciones. En la monarquía, por ejemplo, deben considerarse todas las familias ciudadanas para acceder al Consejo Real y otros cargos (TP 6/15, 21 y 23), sin dejar a ninguna clase fuera y evitando la concentración del poder en pocas manos, de forma que al final coincida la utilidad del conjunto con la mayoría de los votos (TP 7/4). Los diferentes sectores se contrapesan entre sí y los votos resultan en verdad representativos de la sociedad, sin exclusiones. Otro tanto ocurre en el régimen aristocrático, donde "la ley primordial de este Estado debe ser aquella por la que se determina la proporción entre el número de los patricios y el de la población" (TP 8/13); equilibrio que se extiende a todas las instancias del poder a través de una ratio fija entre cargos públicos y habitantes (TP 8/22). Finalmente, lo mismo se dice de los consejeros enviados por las ciudades en función del número de ciudadanos, pues la meta última -aquí se habla de la monarquía, pero resulta generalizable- es crear un "Estado proporcionado" en todos los ámbitos para sostener así a una "multitud libre", la única a la que esto le resulta útil (TP $7 / 18^{17}$ y $26^{18}$ ). La proporcionalidad es la fórmula escrupulosa para canalizar el derecho o potencia de los individuos (agrupados en familias políticas y ciudades), así como en la articulación de un todo estatal operativo: sólo una relación de relaciones equilibrada garantiza el

\footnotetext{
${ }^{17}$ Ahí se añade la máxima general: "En efecto, el poder del Estado y, por lo mismo, su derecho debe ser medido por el número de ciudadanos", de manera que la proporcionalidad permite "mantener esta igualdad entre los ciudadanos (...) pues todos los hombres son de tal naturaleza, que cada uno quiere ser adscrito a su propio género y ser diferenciado de los demás por su estirpe" (TP 7/18). La igualdad, por tanto, se da en la diferencia.

${ }^{18}$ Podría decirse entonces que las proporciones están al servicio indirecto de la libertad de los ciudadanos.
} 
bien público y la paz, en la medida en que compone, unifica y distribuye el poder al mismo tiempo. Un modelo semejante debe regir la selección y el funcionamiento de tales instancias, como se ve en la regulación de los procesos electorales, la duración de los mandatos o la sustitución gradual de los cargos, las edades mínimas para ser elegidos, las fechas de reunión de asambleas, etc. (por ejemplo, TP 8/ 30, 34, 35, 15, 16). Parece claro que el lenguaje numérico de las diversas normas tiene por finalidad asegurar la transparencia y el reparto equitativo, así como evitar la entropía y la corrupción. Los rigurosos procedimientos aseguran el ajuste correcto entre las instituciones, al igual que la circulación de elementos regeneradores -como en el cuerpo humano- entre aquéllas y la sociedad civil. Tales proporciones, reglas y flujos de personas permiten saber a qué atenerse (forma) y prevenir la esclerosis mediante la renovación en todos sus niveles (proceso), de modo que al final se consigue un efecto incluyente y autorregulador.

4.2. Por analogía con la esencia o conatus de cada individuo (según E3P7), reverso dinámico de la proporción de $\mathrm{M} / \mathrm{R}$ que aglutina a los cuerpos, el Estado busca preservarse por encima de todo, para lo cual aumenta sus recursos y llegado el caso repele las agresiones. La independencia vigorosa, pues, sólo se logra con un firme apoyo en la fuerza y en la riqueza, por ejemplo con grandes ciudades bien defendidas; y, en este sentido, la seguridad tiene un sesgo armado y la libertad otro económico, de forma que ambas se complementan una vez más en tanto que soportes del poder y de la autonomía de los ciudadanos (TP 7/16,17). Ahora bien, Spinoza sabe que la paz es mucho más fecunda y productiva, luego debe evitarse la guerra "por todos los medios" (TP 7/28) en aras del bienestar general. Como siempre, nuestro autor se presenta como un pragmático cualificado (ni ingenuo ni depredador) y enemigo de las retóricas al uso, sean legitimadoras de la fuerza bruta o idealistas y ajenas a la crudeza de las relaciones internacionales. Así como más arriba primaban aspectos internos de organización entre las partes del Estado, ahora le toca el turno al desenvolvimiento del sujeto político como un todo de cara al exterior, en el que también es una parte entre otras. De ahí que las alianzas y los pactos sean muy aconsejables (son un grado de composición mayor y una suma de fuerzas), pero siempre subordinados a la utilidad y a los intereses del Estado en cada momento.

Por lo demás, Spinoza desarrolla estos temas procurando de nuevo que haya mecanismos precisos de control, bien sea en la propiedad de la tierra (pública en la monarquía y privada en la aristocracia), en los impuestos y en los sueldos, en la asignación de porcentajes de los beneficios del comercio, en la prestación del servicio de armas para la autodefensa y en el control civil (incluida una duración tasada) del mando militar para evitar el cesarismo, etc. (Véanse, por ejemplo, TP 6/12, 29; $7 / 21,22 ;$ y 8/9). Los derechos y los deberes no son solo formales, sino también $m a$ teriales, de ahí que haya que hablar el lenguaje de las obligaciones y los beneficios 
concretos que los dan contenido en los más variados ámbitos, donde importa que estén bien repartidos en aras del equilibrio del conjunto y que todos asuman sus responsabilidades. A la postre, por lo que se refiere a la gobernación, se trata de que haya engranajes concertados de tal forma que "los funcionarios que velan por los asuntos públicos sirvan mejor a sus intereses cuanto mejor velan por el bien común", con el añadido de que sus ganancias dependan de la paz y no de la guerra (TP 8/24, 31). Hay que componer deseos dispares, sin duda, anteponiendo la supervivencia global mediante el compromiso de todos los ciudadanos con los asuntos capitales que comparten: los genuinos inter-eses, es decir, los que están en medio (según la etimología) sirven de cemento social. El Estado se define por la capacidad de asimilación y por la satisfacción casi metabólica de las necesidades y los apetitos primordiales, además de por su eficacia resolutiva como cualquier otro organismo vivo. Las proporciones apuntadas más arriba son como el esqueleto de un individuo-sociedad recubierto ahora con esta carne palpitante que actúa.

4.3. Por analogía con la conciencia de sí que el individuo adquiere a través del contacto con el mundo (lo que da lugar al procesamiento de informaciones, afectos, ideas, etc.), el Estado es sensible a ciertas relaciones de inteligibilidad que le permiten observarse a sí mismo y modificarse si es preciso. Con otras palabras, también aquí -como en el deseo humano- hay una constitución variable (E3Def.Aff.), en cuanto que admite un aprendizaje que afina sus capacidades: en sentido legal (reformas posibles del status civilis, TP 7/25); en sentido moral (promoción constante de la virtud de los ciudadanos y del respeto a la ley, TP 5/2,3); en sentido administrativo (según la calidad de la gestión por parte de sus responsables, a su vez sometidos a relaciones burocráticas entre ellos, TP 6/19); y, en general, en todo cuanto tiende a asegurar el acuerdo que aúna fuerzas, dada la "interdependencia" de todos los asuntos y de los agentes políticos implicados (TP 7/8, 11). Puede decirse entonces que la sociedad adquiere alguna autoconciencia por medio de tantas conexiones e interacciones internas y externas, lo que conlleva un cierto tipo de conocimiento y de plasticidad que se usan cual instrumentos necesarios para evitar que un conatus político tan pujante como el descrito en el punto anterior degenere en mera inercia o rigidez.

A ello se suman otros aspectos también ligados al conocimiento, en este sentido amplio: así, la toma de postura de Spinoza contra los secretos de Estado, pues conducen a la servidumbre y a la tiranía so pretexto de proteger la seguridad, e impiden el juicio informado de la multitud (TP 7/29); o, por dar un ejemplo diferente, la reglamentación estricta del voto con bolas de colores, en secreto y en público, según las circunstancias y los asuntos, en beneficio de la libertad personal de decisión y de la equidad (TP 8/27, 28); o la prohibición de obtener información mediante tortura, para salvaguardar la justicia y moderar al máximo la economía del miedo (TP 6/26; 
$8 / 41)^{19} \ldots$ Son todas expresiones de una voluntad que reclama luz y taquígrafos, es decir, una libre circulación del saber y un rechazo a la opacidad y la falta de garantías, donde impera el espíritu ya conocido de potenciar los bienes y suavizar cuanto sea posible los males, pues el pensador holandés sabe que la política se mueve en una escala de grados pero con mínimos irrenunciables. Cuando haya datos fiables al alcance de la población, un ejercicio efectivo de derechos, unos mecanismos de decisión transparentes, ausencia de amenazas ilegales o de ocultación, etc., sólo entonces habrá algo que merezca el nombre de libertad. Las personas y los Estados necesitan reglas claras de juego y eso implica alimentar su capacidad ejecutiva por distintos canales de información y actuación, de modo que una vez más es prioritaria una regeneración permanente del sistema que evite los abusos y ofrezca iguales garantías de seguridad para todos.

4.4. Por analogía con las facultades del individuo compuesto y reflexivo, que giran en torno al equilibrio dinámico, a la mutua relación de dependencia e independencia ad intra (entre las partes) y ad extra (entre otros conjuntos o todos), es mucho mejor concebir el Estado completo, compacto, estable..., y en este sentido absoluto y acorde con la razón, pero no absolutista en cuanto que aplaste la pluralidad (el ejemplo de las familias en la aristocracia es elocuente, TP 8/3, 5, 7). La unión y la fuerza se alimentan de tal diversidad, sabia paradoja que rechaza por igual lo que fragmenta y lo que homogeniza: así como el todo es más que la suma de las partes, así también las partes no son reducibles por completo al todo ${ }^{20} \mathrm{y}$ la vitalidad de éstas es condición del vigor de aquél. Esto se traduce en unas medidas que buscan el establecimiento de contrapesos y la descentralización, lo que refuerza el carácter distributivo del poder como principio regulador general. Para ilustrar lo primero vale el apunte (no desarrollado por Spinoza) de lo que serían los poderes legislativo, ejecutivo y judicial, tal como aparecen en las instituciones del Consejo de patricios (legislativo), donde podría distinguirse al menos una doble línea: a) senado, secciones y cónsules, gobernadores (ejecutivo); b) síndicos y tribunales (judicial). Y todos ellos sometidos a elecciones y a rotación. Más allá de los detalles, el autor resume el espíritu de su proyecto así: "Hemos establecido que la suprema potestad del Estado resida en todos los patricios, la autoridad, en cambio, en los síndicos y en el Senado y, finalmente, el derecho a convocar el Senado y (de proponerle) los asuntos relativos al bien común, en los cónsules, elegidos del mismo Senado" (TP 8/44). Reparto de atribuciones a la hora de tomar iniciativas y de gestionar, con el propósito obvio del control mutuo y de que se rindan cuentas de una u otra forma.

\footnotetext{
${ }^{19}$ En el contexto, se busca defender a la plebe de los abusos judiciales de los patricios y los síndicos ejercen esa labor.

${ }^{20}$ Spinoza deja claro a menudo que, en última instancia, "los hombres dotados de razón nunca renuncian a su derecho hasta el punto de que dejen de ser hombres y sean tratados como ganado" (TP 7/25). Es harto conocida su confrontación con Hobbes al respecto en la Epístola 50.
} 
Por otro lado, el modelo federal del Estado (obviamente inspirado en las Provincias Unidas de la época) lleva a las últimas consecuencias la idea física de una composición de escalas, con la consiguiente descentralización. Por ejemplo, en el régimen aristocrático se articula el ámbito local con el nacional de modo coherente: la federación de ciudades (que tienen sus propios consejos, tribunales, etc.) se halla representada proporcionalmente en los consejos supremos (Senado y tribunal superior, que también tienen carácter arbitral, ejército); y hasta la sede de éstos es rotatoria pues no hay capital fija (TP 9/ 3, 4, 5, 6 y 7). El resultado es una concepción policéntrica, basada en el acuerdo, pero este objetivo es logrado a partir de la autonomía y la posibilidad de disenso (la parte-ciudad puede ratificar o no las decisiones del todo-estado ${ }^{21}$, así como en la proximidad de la gestión al ciudadano. La riqueza de niveles e instituciones fomenta toda clase de contactos y la circulación de informaciones y bienes, hasta conformar un gran ecosistema constituido por sistemas abiertos y articulados a través de múltiples canales. Repartir el poder dificulta además un posible golpe de mano autoritario (TP 9/14,15) e instaura un modelo simbiótico -por encima de los conflictos y la natural competencia-, con la consecuencia de que esta extensión del poder es en sí misma una extensión de la libertad.

Es fácil apreciar la complementariedad de estas cuatro perspectivas en el diseño de los principios rectores del Estado, que es sujeto y objeto político a la vez. De hecho, cabe hablar metafóricamente -según el mismo orden seguido en la exposición- de un primer nivel físico, más arquitectónico y básico; de otro biológico u orgánico, que le da contenido vital y movilidad; de una tercera connotación intelectual o reflexiva de la sociedad y sus instituciones; y de un último aspecto propiamente social, nacido de las inter-relaciones distributivas del poder y entre los diversos estados. Los cuatro planos se erigen desde dentro de un mismo modelo y son atravesados por líneas comunes, tales como los vínculos entre autonomía y cooperación, potencia y equilibrio, orden y pluralidad..., siempre en términos de organización proporcional y regeneración constante. Spinoza conoce bien las dificultades y sabe que no bastan los esquemas teóricos, quizá por eso propone pautas flexibles a la par que rigurosas, en las que importa el sentido global (geométrico y aritmético amén de orgánico) del poder, por encima de una u otra realización concreta. La forma física de la política es prioritaria, pero con la posibilidad de adaptarse a ellas (en vez de imponerse de manera abstracta) gracias al sesgo informacional del diseño: proporciones (que transforman cantidades en cualidades sistémicas), circulación frecuente de todo tipo de elementos, interacciones regladas, compensaciones y reajustes...

\footnotetext{
${ }^{21}$ Se trata de "enlazarlas a todas (las ciudades) mediante estos vínculos de forma que cada una se mantenga, en la medida de lo posible, autónoma" (TP 9/4). Unidad en la pluralidad, según reiteramos, pero bien explicitada.
} 


\section{Física de la multitud: la democracia}

El asunto no tiene fácil tratamiento -conviene recordarlo- porque la muerte no permitió a Spinoza exponer al completo su pensamiento sobre el que consideraba el mejor de los regímenes, por más que la apuesta por la democracia ya sea en sí misma algo extraordinario en el siglo XVII. La ventaja de hacer una lectura física como la presente es que permite ceñirse a unas constantes y unos fundamentos contrastados, de manera que no hace falta inventar teorías revolucionarias. Lo cual no impide que sea problemático pensar en una física de la multitud (última depositaria del derecho en tanto que "poder conjunto", TP 3/9), pues la idea misma de que haya proporciones debe tener otros matices. La cuestión es cómo lograr la máxima presencia del poder (ligada a ciertos parámetros de igualdad) con la mínima mediación política, dado que ésta es insoslayable para un autor que comprende la dificultad de la convivencia y desconfía de la acción directa de una plebe a menudo manipulada y/o enardecida. Podría decirse que se trata de construir un ecosistema político aún más dúctil y fluido en sus circuitos, con las menores resistencias posibles a la transmisión de las potencias individuales y que se acerque a la transparencia en la gestión, por difícil que sea la tarea.

Spinoza aporta algunos datos de gran relevancia en su aproximación a la democracia y aquí los engarzamos con nuestra lectura: los hombres ceden mediante pacto su derecho particular a toda la sociedad (no a alguien en concreto), lo que en adelante les obliga a obedecer ciertas normas; pero lo singular del caso es que el sistema democrático "es el más natural y el que más se aproxima a la libertad que la naturaleza concede a cada individuo. Pues en este Estado nadie transfiere a otro su derecho natural hasta el punto de que no se le consulte nada en lo sucesivo, sino que lo entrega a la mayor parte de toda la sociedad, de la que él es una parte. En este sentido, siguen siendo todos iguales, como antes en el estado natural", por lo que las opciones de libertad son máximas (TTP 16: 195). La democracia permite la conexión más directa, en los diversos planos que mienta el texto, entre libertad e igualdad, naturaleza y sociedad, partes y todo, pues se trata de reducir cuanto sea posible la distancia entre cada uno de los miembros de esas parejas. Nótese que las tres expresan -respectivamente- el fin y el medio de la política, los dos niveles básicos de constitución de los humanos y el modelo binario lógico-ontológico que preside todo el sistema. El hilo conductor que los unifica es la potencia, pues en todo momento se habla de cómo expresarla mejor y ser más autónomos (sui iuris) por el hecho de perder menos derecho natural dentro del estado civil democrático ${ }^{22}$. Luego hay que seguir ocupándose de

\footnotetext{
${ }^{22}$ Como ha señalado André Santos Campos (Jus sive potentia. Direito natural e Individuçao em Spinoza, Lisboa, Centro de Filosofia da Universidade da Lisboa, 2010, p. 303 ss.), la frecuente expresión espinoziana de potentia multitudinis se refiere a la potencia de los múltiples individuos que viven en común, no a la potencia del conjunto unificado.
} 
una física de la potencia que permita esa concertación de aspectos, para lo cual volvemos a la noción de cuerpo en tanto que plataforma básica: es (inter)activo, todos son iguales y naturales en su estructura, y es el mínimo común denominador de la multitud constituida en sociedad.

Desde ahí se entiende la definición del pensador holandés: la democracia es "la asociación general de los hombres, que posee colegiadamente el supremo derecho a todo lo que puede" (TTP 16: 193), y para buscar el bien común según el dictamen de la razón hay que unificar en alguna medida los cuerpos y los afectos, como es conocido. Pues bien, el poder común es el resultado de integrar el de los miembros del Estado, pero es la ley la que establece quiénes lo son y gozan de derechos: todos los individuos en principio pueden votar y son elegibles, lo que diferencia este modelo del aristocrático, sometido a más restricciones porque hay “elección” según la pertenencia de clase y la herencia, y porque a menudo se violenta la legalidad por imposición de los oligarcas (TP 11/1,2). La diferencia entre los dos tipos de Estado radica en que el democrático no exige condición previa ni voluntad que esté por encima o al margen de la ley, aunque lo delicado es su formulación concreta. No cabe discutir ahora la exclusión (lamentable para los ojos actuales) que niega la plena ciudadanía por causa del sexo o de otros motivos (económicos, de extranjería, penales...), según propone Spinoza, sino subrayar que él mismo insiste en que solo menciona una de las diversas variantes posibles de Estado democrático: la que se funda en el imperio de una ley según la cual son ciudadanos de pleno derecho quienes cumplan unos requisitos de autonomía y honradez (TP 11/3). Luego la pertenencia natural de los cuerpos a una comunidad y a un territorio (la patria) queda limitada por leyes convencionales, lo que circunscribe las potencias individuales que pueden pertenecer al Consejo Supremo y desempeñar cargos o no.

La ley positiva recorta la igualdad básica de la multitud, aunque en menor medida que otros regímenes, dada su pretensión universalista al margen de una "ley natural" jerárquica o de casta. De hecho, podría ser cambiada con facilidad y no se olvide que la multitud es la instancia última de decisión respecto a sí misma, pues tiene poder autoconstituyente. El autor judío no habla aquí de proporciones, sino de la participación directa de los ciudadanos en cónclaves que elegirán a los gobernantes y acordarán las leyes: el "poder colegial" los hace obedecerse a sí mismos, ya que el poder "está en manos de todos", las leyes "son sancionadas por el consenso general" y el pueblo no se somete a la autoridad de otro, sino que actúa por "su propio consentimiento" (TTP 5: 74). La libertad descansa en las leyes así instituidas, las mismas que dan forma a la sociedad en cuanto que reconocen un derecho de ciudadanía participativo. Ahora bien, nunca dejará de ser problemático gobernar mediante mayorías estables (asamblearias), amén de conciliar las tensiones ya apuntadas (libertad y seguridad, exclusiones legales, diferencias de facto entre individuos y capacidad derivada de presión, etc.). 
Lo que se persigue, por condensarlo en una idea, es un acuerdo que rebase al miedo, donde la virtud entendida como potencia sea algo común y el bien o utilidad un objetivo compartido; todo ello desde, por y para una multitud legalizada, que ya no tiene motivos para armarse o ser anárquica. En sintonía con Maquiavelo y en contra de Hobbes, no existe la demofobia tan habitual en la tradición ${ }^{23}$, sino un protagonismo reglado de la gente (que se filtra a sí misma, por decirlo así). Y el Estado democrático es el que mejor lo canaliza todo dando cabida no tanto al mayor número ${ }^{24}$, sino a individuos de tipos y clases no predeterminadas (quizá más numerosas y amplias), lo que contribuye a la sensatez (fruto del contraste interno entre los muchos diferentes) y a la mayor representatividad en las decisiones adoptadas. En términos sistémicos, la excelencia de la democracia reside en afirmar más y mejor el todo y las partes, dado que la ciudadanía se autodetermina a la par que convierte la independencia de los sujetos en estrictamente recíproca de la dependencia (de la potencia global y de la ley), sostenido todo ello por la participación en las decisiones. De ahí el carácter hologramático del enfoque, ahora aún más logrado: el todo estatal está muy presente en la parte-ciudadano porque éste lo hace suyo cuando se afirma a sí mismo a través de los derechos adquiridos.

Con otras palabras, se concilia mejor la igualdad ante la ley con la diferencia personal que, a su vez, asume como propios los consensos básicos y la cohesión del conjunto. Es claro que la noción de igualdad es polisémica y tal vez paradójica: todos son iguales en tanto que tienen un derecho natural (o fuerza)... distinto; la naturaleza humana y sus pasiones son universales a la par que cambian en las personas según sus biografías y el uso de la razón que hagan; la ley democrática reconoce y da mejor cauce a la libertad o potencia de cada uno, pero homologándolas; nadie quiere obedecer a sus iguales y muchos quedan fuera de ese reconocimiento legal de plenos derechos, etc. Por este motivo añadido y por los inevitables conflictos que Spinoza

\footnotetext{
23 "Quizá lo que acabo de escribir sea recibido con una sonrisa por parte de aquellos que sólo aplican a la plebe los vicios inherentes a todos los mortales (...) Pero lo cierto es que la naturaleza es una y la misma en todos. Sin embargo, nos dejamos engañar por el poder y la cultura, y de ahí que digamos a menudo, ante dos que hacen lo mismo, que éste lo puede hacer impunemente y aquél no... Lo característico de quienes mandan es la soberbia (...) Que, por otra parte, el vulgo no tiene moderación alguna y que causa pavor, si no lo tiene, se debe a que la libertad y la esclavitud no se mezclan fácilmente. Finalmente, que la plebe carece en absoluto de verdad y de juicio, no es nada extraño, cuando los principales asuntos del Estado se tratan a sus espaldas y ella no puede sino hacer conjeturas con los escasos datos que no se pueden ocultar" (TP 7/27). Spinoza arremete contra las clases dominantes y el encubrimiento (con encanto y lujo, con "cierta cultura en la necedad y cierta elegancia en la indecencia") de sus vicios, que en verdad son "repugnantes y vergonzosos" (ibidem). Igualdad básica de la naturaleza humana, por tanto, y sólo diferencia de medios sociales. ${ }^{24}$ En términos absolutos podría ser menor que en la aristocracia, según sean los criterios fijados por la ley (TP 11/2).
} 
siempre contempla, parece que hay tensiones irreductibles en todo ensamblaje político, acaso como ingredientes necesarios que lo hacen dinámico. Y la criba legal del derecho de ciudadanía se ha podido prever para suavizarlas, además de evitar la dificultad de una gestión asamblearia masiva (en los diversos niveles) y, más aún, para reducir las eventuales manipulaciones ejercidas sobre los subordinados y los no autónomos, si éstos tuvieran derecho a voto. Aunque eso no nos convenza hoy...

A falta de los detalles que el filósofo no pudo dar, es necesario recoger los elementos físicos del apartado anterior y aplicarlos ahora, dado que el sistema que mayores posibilidades tiene de limitar su erosión y regenerarse cual deben hacer los cuerpos (TP 10/1) $)^{25}$ es la democracia, el más flexible e integrador, el más terapéutico y educativo. Recuérdese que facilita como ninguno el despliegue pacífico de los deseos particulares, lo que fomenta el compromiso y el acuerdo; además combate el riesgo de oligarquización al incluir -si así se decide- mayor variedad de sujetos y grupos sociales, lo que a su vez mejora la distribución del poder y de los contrapesos, amén de la circulación de las informaciones. La ley universal de ciudadanía (el vehículo para ordenar a la multitud) permitiría intensificar las virtudes ecosistémicas ya conocidas: se da la opción de que haya más tipos de agentes y más complejidad interna en el Consejo, más apertura a la sociedad en consecuencia, más energía y solidaridad actualizada en la asamblea, por decirlo así, menores mediaciones estamentales y entropías de clan, más participación informada y sobre todo más corresponsabilidad. Frente a la desconfianza perenne en la acción política de la masa popular, la física de la democracia así entendida aporta elementos para salvaguardar en la práctica la isonomía y evitar la desmovilización que sólo a unos pocos interesa (la indiferencia de la mayoría es a menudo inducida), como bien sabemos hoy ${ }^{26}$. Pero el pensador holandés no concreta los criterios preferibles de ciudadanía, pues se limita a mencionar como hipótesis la edad, la primogenitura o el nivel de renta, dando margen a la decisión de cada estado. Tampoco parece que defienda una acción sin administradores, lo que engendraría caos, mientras que toda física es una forma de orden selectivo basado en las correlaciones corpóreas, afectivas, de fuerzas e intereses, legales, etc., según muestran los términos usados antes.

\footnotetext{
${ }^{25}$ Spinoza se refiere ahí expresamente a esa necesidad en el régimen aristocrático y cita a Maquiavelo como agudo precursor, pero la idea parece generalizable en la intención.

${ }^{26}$ En palabras de A. Escohotado que glosan la complejidad social y proponen la democracia directa en todo cuanto sea posible: "Tras milenios de sufrir otras modalidades de orden, el experimento del número - confiar en la cordura media de nuestro prójimo- ha obligado ya al gobernante a buscarse un apoyo distinto de la deidad, el ejército o cualquier otro tipo de amenazadora instancia mesiánica. Y en el Primer Mundo bastan unas semanas sin el respaldo efectivo de la población para que cualquier equipo de gobierno, incluyendo a su jefe, dimita o sea procesado por abuso de poder. Esto implica que, finalmente, se ponen en la misma línea de salida los criterios: a igualdad de información, decidirá mejor quien menos hipotecas arrastre". La democracia busca ante todo el autogobierno basado en "la
} 


\section{Epílogo}

Spinoza no propone una emancipación utópica de las masas, tal como ha soñado la Modernidad hasta cierto punto, sino que da pasos en esa dirección desde categorías mentales y conceptuales que no anticipan ni las liberal-burguesas ni las revolucionarias, por resumir, además de que no se adhiere a ninguna idea historicista de progreso. Tampoco cabe hablar de una meta anarco-libertaria o de un asociacionismo ciudadano sin medida, pues la organización del poder que defiende es siempre fuerte, no incluye la legalización de la disidencia como oposición política y limita la autogestión a las instituciones. Podría añadirse que en este discurso no hay una distinción neta entre lo societario y lo comunitario (Gesellschaft y Gemeinschaft), de manera que la civilidad atraviesa ambos planos y los reúne desde cierto pragmatismo cifrado en la ley y en la conjunción de los afectos. La exterioridad no esencialista del enfoque, apuntada desde el comienzo, no apela a un fundamento último (dios, capital, clase o raza, por ejemplo), tampoco a la universalidad del deber moral o a los valores que vinieron luego a remedarla, sino al acoplamiento (reglado y productivo) de unas potencias en interacción. La física, en fin, como un peculiar modelo de religación civil y de canalización de los deseos, con las ventajas de su neutralidad flexible y con las limitaciones propias de una mirada básicamente a-histórica.

Si pensamos en adaptar el autor al presente, resultará fecundo que se oriente hacia un mundo globalizado que necesita nuevas proporciones en el reparto del poder para su gobernanza ${ }^{27}$, aunque la condición actual es en todos los sentidos mucho más móvil y temporaria, más líquida ${ }^{28}$. La nueva política en la época de la complejidad histórico-

\footnotetext{
igualdad de oportunidades para todos" (algo a establecer, conservar y ampliar), a su vez fundado en la virtud cívica de cuño republicano, la libre competencia también política y los recursos telemáticos del presente para ejercer el poder decisorio continuadamente (Caos y orden, Madrid, Espasa Calpe, 1999, p. 312 ss.). En caso contrario, la tutela o el descarado secuestro del poder por unos pocos seguirán presentes: aunque se hayan probado falsas las razones que en su día se esgrimieron a favor del voto censitario, solo masculino, etc., hoy se reeditan-actualizadas-a propósito de la fácil manipulación de las conciencias populares, la supuesta necesidad de expertos, etc., cf. pp. 301 ss.

${ }^{27}$ Podría encajar, por ejemplo, con el trabajo de Sassen, S., Territorio, autoridad y derechos: de los ensamblajes medievales a los ensamblajes globales, Madrid, Katz, 2010.

${ }^{28}$ Tomo la metáfora, claro está, de Zygmunt Bauman: "La sociedad `moderna líquida' es aquella en que las condiciones de actuación de sus miembros cambian antes de que las formas de actuar se consoliden en unos hábitos y en una rutina determinada. La liquidez de la vida y la de la sociedad se alimentan y se refuerzan mutuamente. La vida líquida, como la sociedad moderna líquida, no pueden mantener su forma ni su rumbo durante mucho tiempo (...) si, por una parte, nos son desconocidas la mayoría (si no la totalidad) de las variables de las ecuaciones, por otra, ninguna estimación de la evolución futura puede ser considerada plena y verdaderamente fiable", Vida líquida, Barcelona, Paidós, 2006, p. 9. Evidentemente, Spinoza no pensaba en esta "vida precaria", con una "incertidumbre constante" (p. 10) que ahonda la injusticia social y aboca a lo que podríamos llamar la fungibilidad universal que devora a todos los seres vivos.
} 
planetaria, tan deseable como difícil en un terreno magmático, debería equilibrar la actual fluidez de la digitalización y virtualización de la realidad (en particular la economía financiera) con la presencia sólida de su imprescindible base física (material, ecológica, orgánica, institucional...), un poco al estilo spinozano; sin olvidar la importancia sustantiva de lo simbólico, de lo imaginario, lo icónico, etc., ni el nuevo ecosistema telemático e informacional. Y, por encima de todo, debe buscarse una democracia efectiva, mejorada y ampliada incesantemente en sus mecanismos formales, capaz de unir todas esas dimensiones en un modelo viable y solvente. Lo único seguro - la crisis de civilización actual (política, económica, social, ecológica) lo confirma con creces- es que falta mucho para que éste sea el mejor de los mundos posibles, y Spinoza no se conformaría con ello. 